Ochoa-Espitia, K.P. (2019). La envidia artesanal, un mecanismo de protección, emulación y salvaguardia entre artesanas tunjanas. Revista de Antropología y Sociología: VIRAJES, 21(2), 157-183. DOI: 10.17151/rasv.2019.21.2.8

\title{
La envidia artesanal, un mecanismo de protección, emulación y salvaguardia entre artesanas tunjanas
}

KAREN PAOLA OCHOA-ESPITIA*

Recibido: 3 de febrero de 2019

Aprobado: 29 de abril de 2019

Artículo de investigación

\footnotetext{
* Licenciada en artes plásticas de la Universidad Pedagógica y Tecnológica de Colombia, candidata a Magíster en Patrimonio Cultural de la Universidad Pedagógica y Tecnológica de Colombia (UPTC). Tunja, Boyacá, Colombia. E-mail: okarenpaola@gmail.com. (-) ORCID: 0000-0002-5604-9490. Google Scholar.
} 


\title{
Resumen
}

El presente texto se deriva de la investigación acerca de la disminución del oficio del bordado entre las artesanas de la ciudad de Tunja y las posibles estrategias para su salvaguardia. En el artículo, se lleva a cabo una reflexión sobre la manera en que se trasmiten y se protegen los elementos y saberes artesanales. Con este fin, se realizaron entrevistas y encuentros de bordado con artesanas y conocedoras del oficio para identificar la visión que se tiene actualmente del bordado. Como resultado de estas prácticas y discursos recolectados, se interpretó una emoción particular: la envidia. En el medio artesanal, esta emoción se plantea de manera positiva y natural, ya que promueve la observación y la creatividad; asimismo, favorece la protección de bienes artesanales que contienen la esencia de las artesanas bordadoras, al actuar como un mecanismo innato de protección, creatividad y salvaguardia en el ámbito artesanal.

Palabras clave: artesanas, bordado, dechado, mecanismo, envidia.

\section{Handcrafted envy, a mechanism of protection, emulation and safeguarding among Tunjan artisan women}

\begin{abstract}
This text derives from the research on the decrease in the embroidery crafts occupation among the artisan women of the city of Tunja and the possible strategies for its safeguarding. A reflection is made in the article on the way in which elements and handcrafted knowledge are transmitted and protected. To this end, interviews and embroidery meetings were held with artisans and connoisseurs of the trade to identify the current vision of embroidery. As a result of these collected practices and speeches, a particular emotion was interpreted: envy. In the handcraft environment, this emotion is posed in a positive and natural way since it promotes observation and creativity. It also favors the protection of handcrafted products that contain the essence of embroidery artisans, acting as an innate mechanism of protection, creativity and protection in the handcraft field.
\end{abstract}

Key words: female artisans, embroidery, model, mechanism, envy. 


\section{Introducción}

1 presente artículo se inspira en el trabajo de campo de la investigación realizada en la Universidad Pedagógica y Tecnológica de Tunja, Recopilación de la memoria colectiva del bordado en la ciudad de Tunja, cuyo objetivo principal fue develar las causas de la paulatina desaparición del oficio del bordado entre mujeres y artesanas sabedoras de la técnica; así como, determinar los posibles mecanismos para salvaguardar la transmisión y los elementos del oficio. Para ello, se realizaron algunos encuentros de bordado con artesanas textiles y población de diferentes edades interesadas en esta labor; además, se llevaron a cabo entrevistas semiestructuradas a amas de casa, comunidades religiosas y artesanas textiles tunjanas.

Para el presente artículo se tomó el segmento de las artesanas textiles entrevistadas, mujeres de avanzada edad, quienes conocieron, practicaron o practican la técnica del bordado, teniendo en cuenta que el oficio artesanal textil es su actividad principal. Estas mujeres aprendieron la técnica del bordado en colegios de monjas, internados, conventos o en su círculo materno. Posteriormente, algunas de ellas enseñaron su saber artesanal en colegios de diferentes municipios del departamento de Boyacá. En algún momento estuvieron agremiadas y hoy cada una trabaja desde su taller a causa de problemas internos entre ellas. Los únicos momentos de encuentro se dan cuando coinciden en ferias artesanales o llevan muestras al laboratorio de Artesanías de Colombia.

Durante las entrevistas y los encuentros de bordado, estas mujeres hablaron del oficio del bordado a mano y de un elemento en particular, el dechado (Figura 1). Este es un objeto que identifica y contiene las diferentes puntadas de bordado; es un libro genuino, un libro de consulta de aguja que posee tan solo una página de tela; contiene las puntadas que la artesana conoce y crea; tiene diferentes tamaños y diversidad de colores, dependiendo del gusto o del estilo de cada bordadora. 


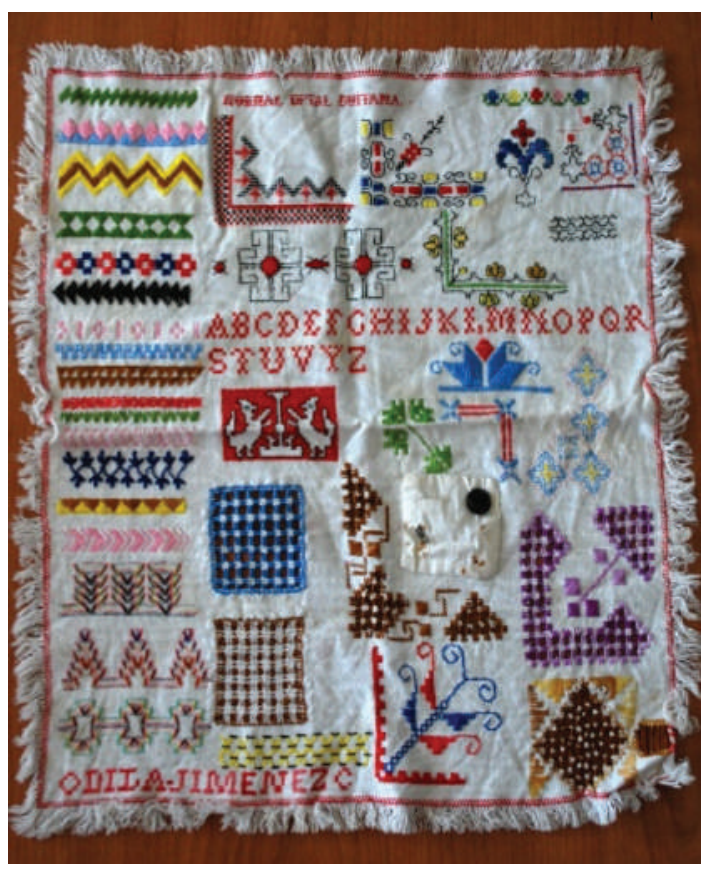

Figura 1. Dechado: una sola página, todas las puntadas de bordado.

Fotografía del dechado de la señora Marlene Jiménez, 2018.

El dechado es identificado como un bien preciado, envidiado y celado, amado por las sabedoras del oficio, pues no es únicamente un libro de consulta; a su vez, se convierte en un elemento narrativo que hace parte de estas mujeres. Esta pieza artesanal guarda el conocimiento del bordado y la destreza que la artesana tiene en cada puntada; contiene el Hau, es decir, el espíritu bordador de la artesana, los conocimientos y habilidades que se entretejen en sus puntadas; como resalta Marcel Mauss (2009), el Hau es "[...] el alma y el poder de las cosas inanimadas y vegetales" (p. 87).

La artesana María García considera el dechado como una herramienta importante de memoria y enseñanza: "Hace falta por dejar lo que uno enseña. A veces se pierde, a veces no, pero es dejar la memoria impresa" (comunicación personal, 22 de agosto de 2017). Esta memoria se encuentra inmersa en el dechado, que ha sido elaborado en el pasado, y resulta importante porque a través del recorrido de la mirada en estos dechados, se recuerdan los modos de hacer y se pueden entender las formas de elaboración de las puntadas ejecutadas por la bordadora. Así mismo, este objeto es una radiografía que evidencia las diversas formas de puntadas implementadas en nuevos trabajos. Vergara (2006) menciona: 
La memoria crea una atmósfera de reconocimiento: vivencias rescatadas de ese otro tiempo en el que todo se aniquila. Pero, también, de retención: el patrimonio actúa como una barrera a la disolución y pérdida total, no de un objeto sin más, sino de una experiencia reconocida en ese objeto y simbolizada por él. (párr. 60)

De esta manera, el dechado actúa como un elemento que renueva la memoria y la experiencia de la bordadora, y evita que se olviden puntadas que serían difíciles de recordar solo con la memoria fotográfica de cada artesana. Al respecto, Mery Galindo comenta:

Primero se hacía el dechado, era muy importante para nosotras, porque de ahí sacábamos las puntadas que debíamos hacer en los manteles o las sábanas de la casa. Luego ya cuando nos pedían pañuelos, sábanas o centros de mesa, sacábamos de ahí las puntadas, (...) era como nuestro libro; si se nos perdía el dechado, se nos perdía el manual y ahí si jum... para recuperar ese trabajo no había lugar. (comunicación personal, 22 de agosto de 2017)

Estos objetos artesanales demandan tiempo y dedicación y llevan las huellas textiles de su realizadora: iniciales, fechas, nombres, diversas gamas cromáticas, puntadas. Algunos se han elaborado a lo largo de varios años; son piezas textiles muy apreciadas por sus dueñas, que les recuerdan no solo puntadas, sino buenos tiempos pasados.

En los diálogos con las artesanas se identificaron diversos sentimientos hacia la técnica del bordado tales como amor, gratitud y nostalgia; virtudes como paciencia, respeto y creatividad, que para ellas es "invento propio", es decir, sus creaciones. Por otro lado, estas conversaciones permitieron identificar una emoción particular: la envidia. Esta última pasa inadvertida entre las mujeres bordadoras, pues no solo se presenta como un sentimiento, sino que se interpreta como un mecanismo propio de salvaguardia y protección de los conocimientos y elementos del oficio; el dechado se describe como un elemento que las artesanas protegen y resguardan bajo este mecanismo. Ello, puesto que la pieza artesanal es evidencia de conocimientos, memoria, tiempo, experiencia y amor por el oficio, elementos visibilizados no solo en la manera en que las artesanas muestran sus dechados, sino en cómo lo guardan, lo celan y lo admiran.

Dicho mecanismo es el único al que pueden recurrir las artesanas, pues no se encuentran familiarizadas con las leyes o métodos de protección de sus elementos, su oficio y sus saberes artesanales. Dos de estas normas son la Ley 23 de 1982, también conocida como Ley de Derechos de Autor, y los 
PES, planes especiales de salvaguardia, que protegen el patrimonio cultural inmaterial. Aquí, es preciso mencionar que los PES funcionan bajo acuerdos entre varios actores, gestores, artesanos o colectivos de artesanos. Por esta razón, resultan complejos de entender y de difícil acceso para las artesanas que no están agremiadas o que no hacen parte de una colectividad, ya que la gran mayoría de las artesanas que hicieron parte de la investigación no están agremiadas, trabajan individualmente en su propio taller.

Así pues, entre las artesanas se genera inconscientemente el mecanismo de la envidia, que les permite proteger sus conocimientos y sus objetos artesanales de sus iguales o de personas que buscan usurpar sus creaciones, regulando quién accede a ellos.

Asimismo, la envidia se interpreta como un elemento que genera e incentiva la creatividad entre ellas. Esta capacidad de creación hace que los individuos quieran alcanzar o mejorar la técnica de su igual. Así, resaltando el lado positivo de este fenómeno, Mandeville (1982) afirma que “La envidia, tan común en los pintores, es de gran utilidad para su perfeccionamiento, [...] como cuando un pintor, esforzándose mucho, logra no solo igualar sino superar al que envidiaba, deja de sentirse inquieto y su tristeza se derrite" (p. 87).

Finalmente, se presentan otros sentimientos ligados a la envidia como los celos y el silencio, de los cuales se plantea una triangulación que respalda el mecanismo de salvaguardia y regulación del saber. Sin embargo, la triangulación genera cierto riesgo para la transmisión de saberes pues celo y silencio culminan en un último elemento, el secreto, siendo este un modo de conservar los objetos y saberes, y compartirlos con un reducido número de personas o círculo de confianza.

\section{El bordado}

El bordado a mano es una técnica de decoración que usa el dibujo en una tela. Esta se ha practicado desde la antigüedad y con diversos materiales: oro, plata, lana, cabello, seda, algodón; también se han empleado diversos materiales sobre los que se borda: seda, algodón, lino, terciopelo, lana, cuero y cualquier tipo de material que permita la entrada de una aguja. Esta técnica se usaba principalmente para decorar ajuares domésticos, como sábanas, fundas, manteles, servilletas, entre otros, y diferentes prendas de vestir. Luz Mery comenta: 
Yo hacía de todo. Yo allá, por ejemplo, cuando estaba en quinto de primaria, yo ya hacía, por ejemplo, en punto de cruz, bordaba manteles para doce puestos, yo bordaba sábanas, sobresábanas, fundas, era todo eso que utiliza uno en la casa, cosas y productos para la casa. (Comunicación personal, 22 de agosto de 2017)

Antes, este era un oficio de práctica casi exclusiva de las mujeres, dentro del hogar, y fue transmitido en diversos espacios: de madres a hijas, en la escuela, colegios (con participación de hombres y mujeres que debían desarrollar trabajos manuales), internados, conventos; este aprendizaje acogió el nombre de trabajos manuales o manualidades. El bordado se practicaba en reuniones a las que se les denominaba costureros, que eran espacios donde se reunían las mujeres para compartir conversaciones y bordar: "En esos encuentros se hablaba de lo cotidiano, de las novelas, la familia, recetas" (Blanca Inés Vásquez Cortés, comunicación personal, 12 de mayo de 2015). Igualmente, recordando la época del colegio, la artesana Luz Mery Guzmán relata cómo era el aprendizaje del oficio del bordado en ese espacio:

Nos sentábamos ahí y charlábamos de la casa, nos reíamos, echábamos chistes, de todo. Eso era como una tertulia ahí que contaba el uno que contaba el otro, hasta inclusive contaban los chinos a veces historias de que ¡Ayi, que es que allí en la casa mi mamá dijo que, que la patasola existía, por ejemplo. ¡No! una historia así. Entonces se ponían y contaban y que es que esta tarde no sé qué y entonces se ponía uno a hablar así. (Comunicación personal, 11 de noviembre de 2016)

Hace pocos años, este oficio se compartía no solo en las casas de familia, sino también en las ferias y talleres artesanales. Según los testimonios de las artesanas textiles de Tunja, el bordado está desapareciendo actualmente. Así, ante la pregunta: “ ¿cómo ve el bordado hoy día?”, Luz Mery responde: "Olvidada y en extinción, [...], yo veo que muy pocas personas están bordando. Prácticamente es que nadie, es que yo las puedo contar con los dedos de la mano" (comunicación personal, 11 de noviembre de 2016). Hoy en día, el bordado no se practica en colectividad; las artesanas entrevistadas ya no están asociadas; cada una borda en su casa o taller; los trabajos que realizan son para sus familias o por encargo de clientes que conocen la técnica y desean que sus prendas lleven algún tipo de bordado. 


\section{La envidia}

Con frecuencia, la envidia es asumida de manera negativa, como lo evidencian las siguientes reflexiones:

La envidia es maladaptativa porque estropea y, en ocasiones, anula completamente el placer de la admiración, el gozo de la amistad, la utilidad del compañerismo y la solidaridad, el júbilo por los logros de otro, la contemplación de la belleza, de la habilidad, del ingenio $\mathrm{y}$, también a veces, el simple deseo de emular al mejor. (Paniagua, 2002, p. 36)

Asimismo, en La Divina Comedia, en su apartado “El Purgatorio, Dante Alighieri", Martínez (2005) comenta: "La envidia me impide comprender, captar la profundidad de su pensamiento. La envidia me cierra los ojos" (p. 29). Por otro lado el mismo autor explica:

La expresión "mal de ojo", se utiliza con frecuencia para designar la envidia. En el mundo primitivo, los individuos tienen miedo de sobresalir, de adquirir más que los demás, porque saben que con ellos desencadenan el odio envidioso, les pueden "echar el mal de ojo" y hacerles brujería. (Martínez, 2005, p. 127)

Más adelante, sostiene: “[...] La envidia es valorada de manera negativa, es un pecado, algo oscuro, peligroso, patológico y está causada por carencia, la inferioridad y el desear o querer" (p. 385).

Sin embargo, a partir del presente análisis del ámbito artesanal, es preciso evidenciar que esta emoción es una forma de protección, regulación y salvaguardia innata de los saberes y conocimientos tradicionales artesanales. De esta manera, se permite la conservación de las formas de pensamiento de las artesanas, la configuración de las relaciones que se tejen en cuanto a dichos saberes, y la manera como el saber es ofrecido en la transmisión del conocimiento en los círculos de confianza.

\section{La envidia como mecanismo de creatividad}

Las diversas caracterizaciones de la envidia como una emoción, una pasión, un pecado capital, un sentimiento y hasta una virtud han dado lugar a varias disertaciones en diferentes campos: artísticos, filosóficos, psicológicos y religiosos. Dentro de estas, es preciso hacer referencia a Kant, Nietzsche, Freud, Spinoza, quienes han abordado la envidia de manera 
negativa; sin embargo, Mandeville la considera como una "pasión útil y provechosa" (Tresguerres, 2003). Por otro lado, "Santo Tomás de Aquino define a la envidia como una infelicidad por los bienes ajenos" (Martínez, 2005, p. 127). Asimismo, hay diferentes tipos de emociones y términos relacionados con esta, tales como, preocupación, posesión, propiedad, rival, sujeto, celos, silencio, entre otros (Centeno, 2017; D'Arms, 2017; Martínez, 2005).

La envidia siempre se genera hacia un elemento externo: un objeto, una persona, un conocimiento o incluso una habilidad. Asimismo, este mecanismo produce deseos de emulación que resultan ser positivos, ya que "la emulación es un motor importante del progreso (en las artes como en las ciencias, o en la propia vida moral)" (Tresguerres, 2003, párr. 1). Así, la envidia también es el resultado de una admiración que promueve la creatividad en los sujetos que la experimentan y que pertenecen al mismo gremio. Tal como lo expone Voltaire (s.f.): "El alfarero envidia al alfarero, el artesano al artesano, el músico al músico, el poeta al poeta, y hasta el pobre envidia al pobre" (Voltaire, párr. 1). Es decir, se envidia a un igual, "Se envidia a quien hace o tiene algo que nosotros nos consideramos perfectamente capaces de hacer o consideramos absolutamente factible poseer" (Tresguerres, 2003, párr. 4).

De esta manera, la envidia es vista aquí no solo como un mecanismo de salvaguardia, sino, además, como un sentimiento positivo que despierta el deseo de emulación; asimismo, la envidia se convierte en admiración e imitación, incluso bajo el deseo de sobrepasar aquella habilidad o mejorar ciertos elementos elaborados. "La envidia de emulación se valora de manera positiva, ya que lleva al sujeto a tratar de mejorar desde un punto de vista social y resulta benéfico desde la perspectiva del individuo" (Martínez, 2005, p. 130).

Para el presente estudio se hará referencia a la artesana-envidiosa. En ella, se genera preocupación cuando experimenta sentimientos de inferioridad o cuando se siente en desventaja al percibir que no posee el mismo bien o posesión (habilidades, elementos o conocimientos) que la otra artesana, a quien se denominará artesana-envidiada.

La envidia en la artesana-envidiosa se activa frente a la artesanaenvidiada con respecto a la posesión del bien patrimonial, precisando que el bien anhelado es la habilidad o conocimiento de la técnica (tipo de puntadas) y del objeto (el dechado) que contiene las puntadas del bordado. Ambos, técnica y objeto, van de la mano ya que contienen la esencia, el tiempo, el rigor y el amor por el oficio; son inseparables, pues provienen de una persona que dedicó gran parte de su tiempo al diseño, creación y elaboración placentera del objeto. Con relación a este fenómeno, la artesana 
Mery Galindo comenta: "este, por ejemplo, se lo robé a una amiga que bordaba rebonitico, se lo pedí prestado en chaques de sacar unas puntadas, pero nunca se lo devolví, a mí me servía más. Ella hizo unas puntadas que yo no hice" (comunicación personal, 22 de agosto de 2017). Hoy en día, el préstamo de estos libros de aguja no se da, pues anteriormente el dechado se pedía prestado, y casi siempre "se quedaba prestado".

De acuerdo con lo anterior, surge la triangulación (Figura 2) en la que se encuentran, por un lado, la artesana-envidiosa, por ejemplo, la señora Mery Galindo, bordadora; por otro lado, la envidiada, la amiga bordadora, dueña original del dechado prestado, en la cima, la posesión, que hace referencia a los conocimientos, habilidades y elementos que se convierten en los bienes patrimoniales del sujeto, en este caso, el dechado: elemento codiciado y envidiado.

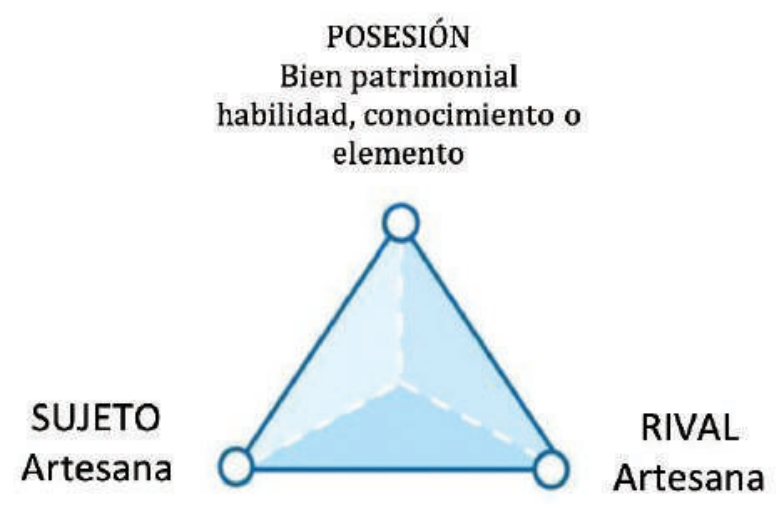

Figura 2. Triangulación de la envidia. La envidia triangula: el sujeto (artesano), el rival (el otro artesano) y la posesión (conocimiento o habilidad, objetos).

Fuente: creación propia.

Como se mencionó, en ocasiones, la envidiosa experimenta diversos sentimientos generados por la envidia. Estos dan origen a reacciones como la admiración, la frustración o la ambición, provocando en la artesana envidiosa el deseo por mejorar o emular lo que ve en la envidiada.

Así, la frustración surge cuando la envidiosa se compara con la envidiada al no tener la misma posesión (saber, habilidad o bien); la artesana-envidiosa se siente en desventaja respecto a su conocimiento. De este modo, la envidia genera una ambición que conlleva a que se enciendan los motores de la creatividad; es allí que se habla de la envidia positiva o emulativa, pues despierta en la envidiosa un deseo por observar, analizar y realizar cierto tipo de puntada, intentando producir una similar o una nueva. Retomando las palabras de Voltaire, la envidia "espabila 
la pereza y agudiza el ingenio de todo el que desea equipararse a otro" (Tresguerres, 2003, párr. 1).

Por ello, gracias a la envidia positiva o emulativa, en el dechado y en trabajos artesanales se incorporan nuevas puntadas que incentivan la creatividad de las artesanas, pues identifican que su envidiada ha elaborado o creado una puntada que puede ser nueva o ha sido mejor ejecutada técnicamente. Por esta razón, surge el deseo de perfeccionar, mejorar o aprender nuevas formas de hacer. Con relación a las puntadas, la señora Mery comenta:

Esta, por ejemplo, que le dicen escapulario, la saqué mirando cómo la hacía una señora en una feria, así he sacado varias que no tenía, A veces con solo mirar uno se da cuenta de cómo se hace la puntada, otras veces toca detallar es el dechado y verle el revés. (Comunicación personal, 22 de agosto de 2017)

En la envidia emulativa o positiva, surgen dos tipos de miradas. Por un lado, se pueden identificar las miradas directas, enfocadas de maestro a aprendiz, donde hay diálogos, pausas y ajustes para aprender, corregir y comentar acerca de la técnica u otros temas personales. Mery Galindo comenta:

Yo inicié a bordar en una feria, un día estaba yo tejiendo y vi que otra artesana estaba bordando unas bellezas, (...) enton, la miraba y la miraba hasta que nos pusimos a hablar y me enseñó unas puntaditas ahí en esos días, a veces nos encontramos por ahí. (comunicación personal, 22 de agosto de 2017)

Así, los encuentros entre artesanas desencadenan envidias positivas o emulativas que permiten intercambiar no solo conocimientos, elementos y palabras sino generar lazos de amistad. Por otro lado, se generan las miradas oblicuas, disimuladas y celosas (Figura 3), donde este deseo por aprender debe ser mimético y ligero para reconstruir y desarrollar luego sus propias puntadas. Por ello, como lo explica Centeno (2017), en el apartado 6.1. La envidia privada o de cómo la envidia se vive de forma oculta, la envidia es: "una pasión intencionalmente oculta y encubierta que se vive en solitario. [...] Se niega ante los demás y ante uno mismo sentir envidia. [...] La envidia revela una deficiencia de la persona que el envidioso no está dispuesto a admitir". Así, en el caso de la artesana Luz Mery, las miradas que ella realizó para identificar la ejecución de la técnica fueron oblicuas, pues no tuvo un diálogo directo con su envidiada: 


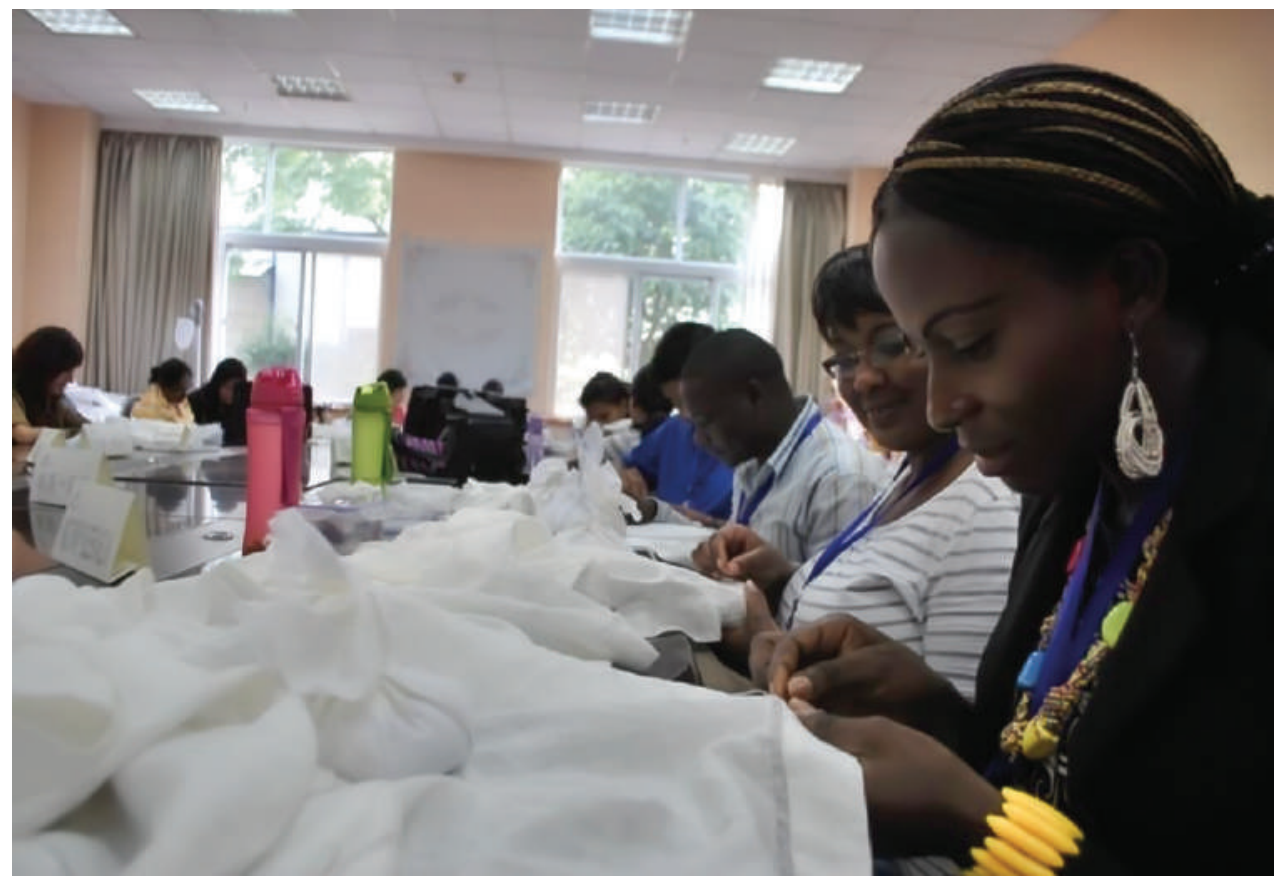

Figura 3. "Una inconsciente envidia hay en la oblicua mirada." (Nietzsche, s.f., p. 82).

Clase de bordado Changsha-China 2015. Elaboración de trabajo bordado con las puntadas de clase.

La artesana de camisa blanca observa el trabajo de su compañera. Se realizan miradas discretas para medir e identificar nuestro trabajo con respecto al otro.

Se usa esta fotografía para identificar las miradas oblicuas, pese a que no son las bordadoras de Tunja reunidas, ya que hoy día no se encuentran asociadas ni trabajan en colectividad, se toma de ejemplo este taller de bordado con artesanas de diferentes partes del mundo para identificar una mirada que se interpreta como emulativa y oblicua.

A mí nadie me lo enseñó y resulta que yo mirando una vez una señora que lo sabía hacer y no más yo lo miré y el tiempo pasó y entonces yo hace poquito eso lo hice para artesanías de Colombia, para la feria en Medellín el año pasado, que hicieron doce cojines y me quedé ese. (Comunicación personal, 11 de noviembre de 2016)

Así mismo, Luz Mery afirma: "Yo lo aprendo todo, todo, yo lo aprendo así, pero no porque me lo enseñen, sino que yo investigo, yo miro cómo se hace y yo lo hago y lo hago bien y me sale bien". De este modo, "El deseo de hacer algo bien es una prueba decisiva [...] perseguir activamente el buen trabajo y descubrir que no se es capaz de hacerlo corroe el sentimiento de autoestima" (Sennett, 2008, p. 67). Por esta razón, la afirmación de la artesana "yo miro cómo se hace y yo lo hago, y lo hago bien y me sale bien", representa un reto consigo misma; su ejercicio emulativo del trabajo 
observado con las miradas oblicuas debe responder a un resultado mimético igual al de su envidiada; su deseo por igualar o mejorar la lleva a desarrollar una puntada o técnica muy similar al de su envidiada.

Así, la envidia casi siempre es silenciosa y también disimulada. Como lo muestra el relato anterior, esto se genera cuando las artesanas ven los trabajos de sus compañeras y encuentran algún elemento que les llama la atención. Algunas veces, algunas indagan sobre la ejecución técnica de la puntada, momento en el que se pueden dar las miradas directas; otras, simplemente miran rápidamente, oblicuamente, para pasar inadvertidas y así poder imitar y luego elaborar sus propias puntadas. Por este motivo, las miradas son miméticas "Solo así el imitador cree que es igual a lo imitado, que lo domina, que lo representa" (Moncada, 2014, p. 176). Como lo mencionan Girbés y Martín (2015): “Van de Ven, Zeelenberg y Pieters (2009), reconocen que la envidia se dirige a una situación de amenaza o desafío para volver a encontrar el equilibrio mediante dos maneras: mirar el objeto envidiado y desarrollar el propio" (p. 2).

Cada artesana sabe que posee atributos que le facilitan los procesos de aprendizaje e innovación o "invento propio" (según ellas). Por ello, todo lo nuevo que elaboren, sea por imitación o descubrimiento, es único e innovador, digno de la admiración de las demás artesanas:

(...) del bordado todo lo que sé lo aprendí mirando, y el gusto por hacer las cosas. No es que haya hecho un curso, nunca en mi vida. Yo no recuerdo de haber hecho un curso. Yo lo que sé es invento mío, es creación, es empírico. Yo nunca hice un curso para nada, sino el gusto por hacer las cosas, por ejemplo, cuando estudiaba en la escuela me gustaba mucho el dibujo, (...) me gustaba el diseño en perspectiva, y ahora se me facilita para el bordado. (...) si ya le digo, todo es invento mío. Yo esto no lo aprendí en ninguna parte, es decir, las puntadas que yo saco y me invento unas puntadas, (...) el cordón, la cadeneta, punto de cuadro, no, no se dé más. Yo de puntadas no sé. Yo hago, así como siento e imagino la imagen. (M. Isabel Cristancho, comunicación personal, 6 de octubre de 2016)

(...) esa ruana de puntas yo fui la que me la inventé porque todo el mundo hacía era ruanas así rectangulares, rectangulares, abiertas, rectangulares, abiertas, cuadradas, pero nada. $Y$ volteando un paño cuadrado que me hizo un señor, y yo decía, pero es que esa ruana me queda cuadrada y me queda muy chiquita y empecé a voltearla, hasta que nos dio la idea de, no sé, quedó así y yo dije mire esto se puede doblar así, ponerle y hacerle y de casualidad nos salió la ruana así y la hicimos, y todo el mundo empezó a copiarse. (Luz Mery Guzmán comunicación personal, 11 de noviembre de 2016) 
El término copiarse mencionado por la artesana Luz Mery alude a la interpretación de envidia que las otras artesanas sintieron de su ruana, que finalmente también hicieron. Para ella, su idea fue original ya que otras no la tenían. Como menciona Sennet (2008): “'Algo donde antes no había nada'. La originalidad marca una época; denota la súbita aparición de algo donde antes no había nada, porque algo adviene súbitamente a la existencia, despierta en nosotros emociones de asombro y veneración" (p. 50).

De este modo, la envidia emulativa hace que el artesano quiera ser reconocido frente a otros mediante cada pieza que crean, la cual visibiliza y lleva impresas historias y sentimientos guardados. En suma, los artesanos perciben que es posible realizar objetos artesanales de otras maneras; experimentan, reinventan, buscan la autosuperación; son investigadores en su oficio y tradición. A diario, se muestran innovadores, creadores y curiosos por generar productos y técnicas que les permitan permanecer en un lugar de referencia.

\section{Posesión o bien patrimonial envidiado}

Como se expuso anteriormente, la envidia se convierte en un motor de creatividad cuando se hace referencia a conocimientos o habilidades. Con relación a ello, Mandeville, citado en Voltaire, afirma que "sin la envidia no hubieran adelantado tanto las artes, y que Rafael no habría sido tan gran pintor si no hubiera envidiado a Miguel Ángel" (Voltaire, s.f.).

En este sentido, el deseo que despierta la envidia por obtener la posesión del otro hace que se generen sentimientos de inconformismo consigo mismo, de desventaja o de carencias técnicas artesanales frente a los conocimientos o posesiones. A su vez, este deseo estimula la admiración hacia el otro, proyectando ciertas miradas estratégicas que conlleven a querer obtener o emular esa propiedad o conocimiento; de esta manera, la envidia incita el deseo de autosuperación. Tal como se lo expresa Savater (2005), en el periódico El Clarín, “admiramos con lo que hay de admirable en nosotros. Nuestra parte admirable es la que admira a los demás" (párr. 11).

La posesión envidiada en el caso de las artesanas bordadoras, es el dechado (Figura 4), un elemento de consulta guardado celosamente, importante y significativo para la memoria y ejecución de las puntadas del bordado. Por ello, al profundizar en el caso de estudio, cabe recordar que las protagonistas son mujeres artesanas tejedoras y bordadoras, quienes, a través de sus relatos en las entrevistas, han dado testimonio de la pérdida de los dechados. En efecto, durante las entrevistas, al solicitar el préstamo o la exhibición de los dechados, se percibió en ellas cierto grado de recelo, 
debido a que la solicitud de préstamo del dechado ha sido pretexto de otras artesanas para ver las puntadas, sin que la pieza hubiera sido devuelta a su dueña, como se expuso en el apartado anterior.

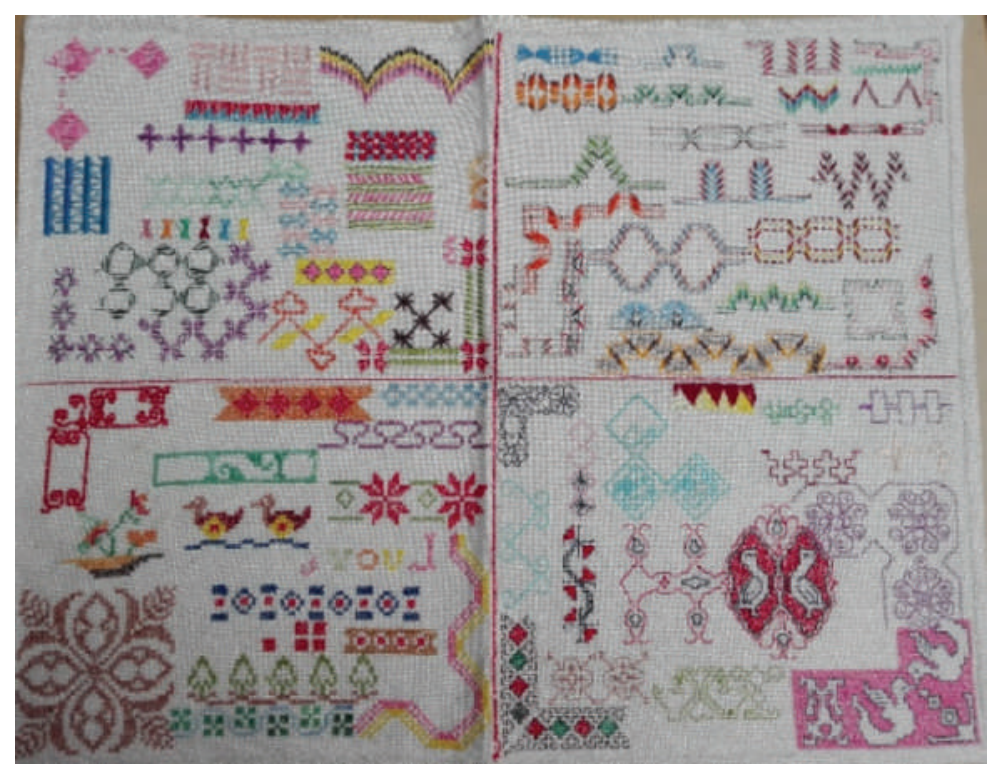

Figura 4. Dechado: elemento de consulta que contiene las puntadas de bordado, convertido en un objeto envidiado y, a su vez, celado por las artesanas que aún conservan esta herramienta artesanal. Fotografía de dechado de la señora Mery, mostrado en la entrevista de 2018.

Así, la artesanía resulta ser no solo un objeto que contiene las puntadas, sino que, a su vez, es un elemento deseado. Esto lleva a acoger la definición que expone D”Arms (2017) en el numeral 7: “[...] la envidia es del bien que tiene el otro; su poseedor juega un papel relativamente menor ya que es meramente la ocasión para que la persona envidiosa se dé cuenta de sus deficiencias".

Los dechados, instrumentos de consulta invaluable que permiten rememorar y reconstruir puntadas: unas elaboradas a lo largo del tiempo, transmitidas por las maestras en tiempos pasados, a través de la mirada y el tacto; otras más actuales, realizadas por invención propia o como resultado de miradas emulativas. Sin embargo, hoy día, no todas las puntadas que se encuentran en los dechados se elaboran debido al grado de complejidad y al tiempo que demandan. Cada dechado es diferente, no hay dos idénticos, estos se elaboran según el aprendizaje, la práctica y destreza de cada bordadora; la mayoría fueron elaborados durante el paso por la primaria y el bachillerato, el colegio, los internados o los conventos. 
En esta pieza artesanal, derecho y revés son importantes para el rastreo técnico de las puntadas. Las bordadoras más audaces pueden determinar cómo ha sido elaborada cada una de ellas; recorren a través de la mirada y el tacto cada puntada que quieren recordar y ejecutar. Debido a ello, para estas mujeres estos elementos son libros de consulta, bienes preciados, objetos artesanales que despiertan emociones, pues contienen cargas emocionales que recuerdan experiencias, aprendizajes y técnicas. De igual manera, el derecho y el revés son consultados constantemente cuando se está bordando con el fin de revisar la ejecución de las puntadas. "Por esto, requiere de una constante atención que facilite su permanencia, o permita su regreso con la misma fuerza vital que alguna vez le dio origen" (Vergara, 2006, p. 61). Así, estas piezas no se prestan, se celan cuidadosamente: "los objetos patrimoniales, ya no pueden concebirse como apartes, sino como algos con los que andamos tramados o entramados, porque nos importan, nos atañen y comprometen" (Vergara, s.f., p.16).

[...] el objeto artesanal guarda impresas, real o metafóricamente, las huellas digitales del que lo hizo. Esas huellas no son la firma del artista (Figura 5), no son un nombre; tampoco son una marca. Son más bien una señal: la cicatriz casi borrada que conmemora la fraternidad original de los hombres. (Paz, 1997, p. 136)

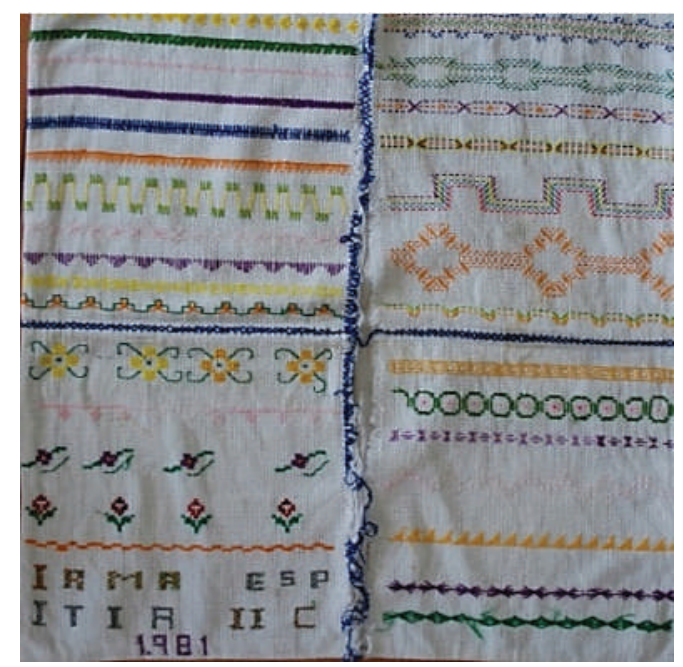

Figura 5. Dechado. Fotografía de dechado de la Señora Irma María Espitia Pérez. Entrevista de 2017. 
Además, este objeto contiene el alma y la esencia de la artesana bordadora pues no sololleva consigo el conocimiento del oficio y las puntadas del bordado; también es un bien patrimonial que tiene vínculo directo con la experiencia, con las narrativas, las emociones y saberes de su creadora: “Un objeto pasa, entonces, a la condición de patrimonio, cuando vive de la memoria, al tiempo que la suscita y realimenta emociones" (Vergara, 2006, párr. 13). Por ello, cuando las artesanas muestran sus dechados, recuerdan las épocas en que realizaron las puntadas; sus narraciones permiten, además, conocer los sistemas de aprendizaje en torno al oficio del bordado. Por ejemplo, Mery Galindo recuerda experiencias escolares del aprendizaje del oficio, al comentar:

La monjita se llamaba Susana Gabriela, y había que hacer necesario alguna manualidad, y que nos ponían a leer en silencio. En esa hora nos tocaba oír la lectura de una novela alguna cosa así de la literatura y había que hacerlo. Se escuchaba la lectura y se iba bordado. La clase era en silencio y alguien estaba leyendo siempre, una novela de la literatura universal, entonces se bordada. (Comunicación personal, 22 de agosto de 2017)

Este objeto rememora (Figura 6) no solo la técnica de las puntadas sino todo un conjunto de eventos en torno a conversaciones, que son importantes para identificar los diferentes modos de aprendizaje con comunidades religiosas o en un colegio tradicional, por ejemplo. Mery Galindo, quien aprendió el oficio en una escuela tradicional, recuerda al respecto:

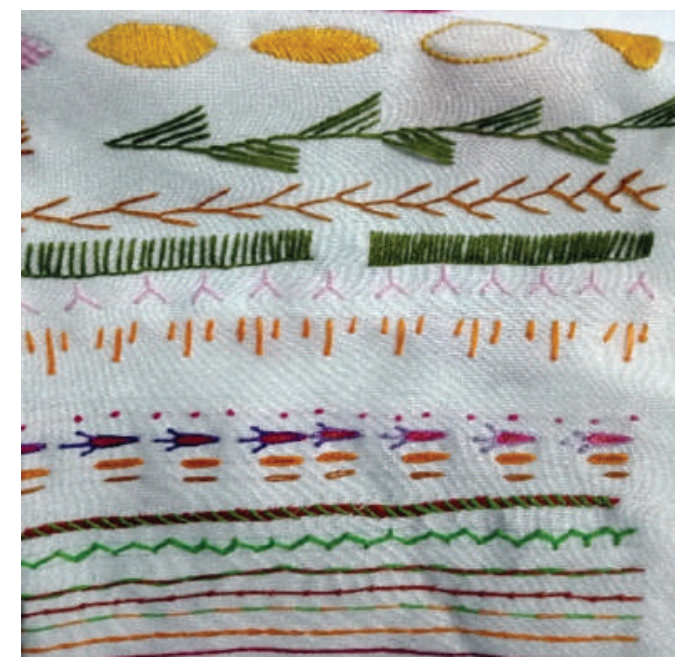

Figura 6. Dechado: Fotografía de un dechado de la señora Luz. Guzmán. Entrevista (2016) 
Nos sentábamos ahí y charlábamos de la casa, nos reíamos, echábamos chistes, de todo. Eso era como una tertulia ahí que contaba el uno que contaba el otro, hasta inclusive contaban los chinos a veces historias de que ¡Ay!, que es que allí en la casa mi mamá dijo que, que la pata sola existía, por ejemplo ¿no?, una historia así, entonces se ponían y contaban esta tarde. (Comunicación personal, 11 de noviembre de 2016)

“Los objetos, por tanto, se relacionan y forman una narración propia y cultural, hasta el punto de poder generar narraciones en el presente desde el pasado" (Gómez-Redondo, 2017, p. 6). Así, estas narraciones abren ventanas para conocer dinámicas y experiencias pasadas alrededor del oficio y de sus modos de transmisión y aprendizaje:

Entonces, la experiencia pertenece a un mundo, ayuda a constituirlo y lo pone a disposición mediante el recuerdo, actuando -en la medida de su vigencia- contra lo efímero de las cosas y contra el olvido. (...). De aquí que la emoción forme parte necesaria de la vivencia. (Vergara, 2006, párr. 13)

Aquí, es posible tomar el testimonio Luz Mery Guzmán y Eloísa García como un claro ejemplo de la pérdida del dechado a causa de la envidia que surge entre las artesanas. Ellas relatan cómo perdieron o, en otras palabras, cómo fue robado su dechado; Eloísa comenta:

[...] lo presté, entre los errores que uno comete, a una señora que vino de Bogotá, y le enseñé de acuerdo a las puntadas que yo tenía en el dechado y luego dijo, ¡Ay! préstemelo que no sé qué; yo vengo tal día. Y no ha vuelto. (Comunicación personal, 10 de octubre de 2016)

\section{Y Luz Mery menciona:}

(...) yo tenía un dechado en donde tenía trescientas cincuenta puntadas. Así de ancho era el dechado y eso era largo, largo, largo, y todo ordenadito; que ese era mi dechado que yo tenía desde que yo era chica que empecé a hacer mis muestras. Y resulta que por ahí una señora un día me dijo que se lo prestara, y me lo hizo perdedizo, y hasta la fecha, nada. (Comunicación personal, 11 de noviembre de 2016)

Por situaciones como las que se atestiguan en los relatos anteriores, actualmente las artesanas cuidan y resguardan con mayor recelo sus dechados; estas piezas se convierten en objetos deseados por sus iguales, es decir, por las demás artesanas. 
Obtener el bien anhelado del envidiado genera un estado de felicidad en quien lo roba, ya que este objeto contiene la esencia que hace diferente a su creadora y que la posesiona en un nivel privilegiado frente a las demás artesanas. Al robarlo, la envidiosa posee parte del conocimiento y la experiencia del bordado de su autora. A su vez, la envidiada pierde una parte de ella, pierde un bien patrimonial que es deseado entre las artesanas bordadoras. Con la pérdida del dechado se extravía un contenido emocional y simbólico que transmite los secretos de elaboración de las puntadas.

Mauricio García (2014) define este tipo de envidia de la siguiente manera: "No se envidia lo que posee el envidiado, sino la imagen que el envidiado proyecta como poseedor del bien" (párr. 1). Así, es preciso resaltar que el elemento tiene la esencia y el don de la artesana envidiada. La envidiada es vista como poseedora de un bien deseado que es evaluado en comparación con el trabajo de la artesana envidiosa. Este objeto contiene el alma, la esencia y la experiencia de la envidiada; y proyecta el nivel de conocimiento, la invención y destreza, haciendo de la envidia un ejercicio comparativo de saberes y habilidades que se quieren emular.

\section{La otra cara de la moneda, el envidiado y los celos}

Se ha hablado de la envidia y de los sentimientos que genera como un aspecto que finalmente lleva a acciones positivas, en pro de un nuevo conocimiento para la envidiosa. Al mismo tiempo, la envidia llega a asociarse o confundirse con sentimientos como los celos, vistos generalmente con negatividad, por lo que la primera obtiene una apreciación negativa. Sin embargo, los celos son considerados en las artesanas como un aspecto positivo, al tomarlos como un elemento que les permite cuidar, celar y regular.

En el arte, los celos han sido representados mediante la figura de un perro en los cuadros artísticos que simbolizan la envidia. En estas alegorías -en los grabados de Jacob Matham (1953) (Figura 7) -, el perro es un elemento que acompaña casi siempre a la mujer y las ninfas. Los celos hacen que el perro perciba, huela, identifique y regule quienes pueden acercarse a su dueña. Así, los celos se convierten en un mecanismo de seguridad y protección de su dueña. 


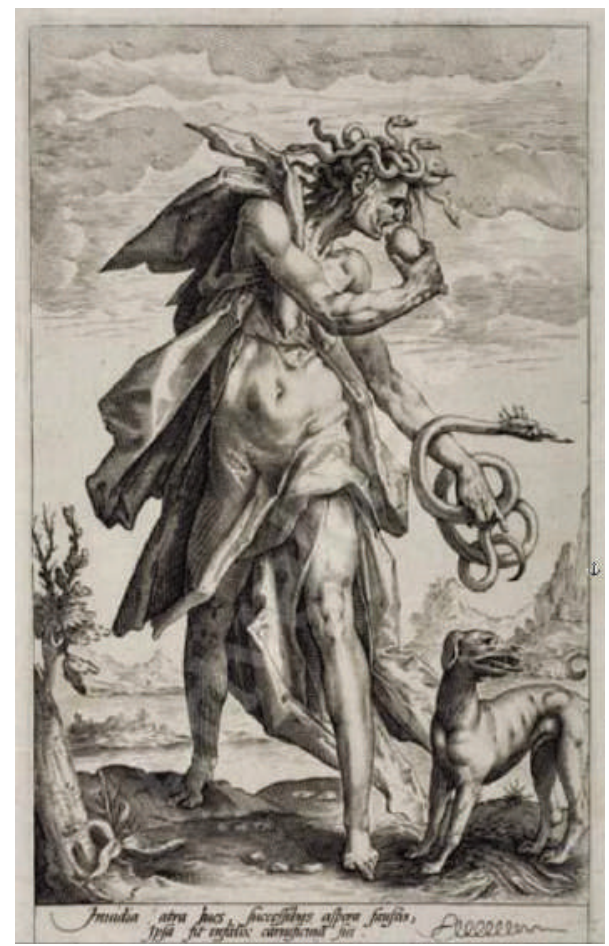

Figura 7. Grabado de la envidia (Matham, 1593).

Al hacer una analogía, los celos que surgen en las artesanas podrían ser comparados con los celos que surgen en el perro, puesto que en ambos casos este sentimiento emerge debido al afecto que se tiene por el objeto o la persona que se cela; aquí se hace referencia al cariño que siente la artesana por su pieza artesanal y al cariño que siente el perro por su amo.

Por otro lado, en la representación pictórica de la Mesa de los Siete Pecados Capitales, de El Bosco (1480), también se puede interpretar la imagen del perro como una alegoría de la envidia. En esta pintura se ven dos canes que desean un hueso sostenido por un hombre; $y$, aunque en el piso tienen dos huesos más, quieren un tercero. En este sentido, la alegoría apunta al continuo deseo de poseer más, como se mencionó anteriormente, se quiere lo que el otro tiene.

La envidia y los celos siempre tendrán un vínculo estrecho entre sí, tal como lo expresa Fernando Savater (2004): “Casi siempre los celos se relacionan con la envidia, pero la diferencia básica es que se siente envidia de lo que uno no tiene y celos de lo que uno tiene" (p. 61); es decir, se cela 
lo que se posee porque no se quiere perder: el ser amado, los objetos, los hermanos, amigos, etc. De manera que, en el caso de estudio, se celan los objetos (dechados) y por consiguiente los conocimientos, que representan para la artesana sus bienes culturales y patrimoniales, en los que reside la esencia de su oficio.

En este sentido, la posesión de la envidiada genera que la preocupación de la envidiosa se centre en la pieza artesanal, pues es la envidiada quien ha desarrollado este bien o conocimiento. Al mismo tiempo, en la envidiada se despierta el celo por cuidar su posesión, ya que es admirada, acechada, y su arte, apetecido.

Durante la investigación, a cada artesana se le solicitó el préstamo del dechado para explorar las muestras de las puntadas; $y$, como mencionó, la respuesta de la mayoría de ellas fue evidencia del actual rechazo al préstamo de sus obras: "si quiere, lo puede ver aquí, pero no se lo puedo prestar" (Mery Galindo, comunicación personal, 22 de agosto de 2017). Blanca Vásquez comenta: "este me lo han intentado robar varias veces. Es que mire, la puntada española casi nadie la sabe hacer, me ha tocado con los ojos encima pa' que no se haga perdedizo" (comunicación personal, mayo 12, 2016). Así, pues, se puede concluir que el envidiado entra en una dinámica en la que debe cuidar sus conocimientos y su bien, pues este es resultado de un trabajo creativo, minucioso y reflexivo. Los celos y la envidia se convierten en mecanismos reguladores que les permite saber a quiénes les comparten sus habilidades o elementos para evitar que les sean usurpados o desvalorados.

Por ello, ser envidiado implica un doble juego. Por un lado, en el artesano se genera un estado de intranquilidad, pues su bien más preciado corre el riesgo de desaparecer por la envidia que genera en los demás. Por el otro, ser envidiado significa estar en un lugar privilegiado, pues el artesano tiene algo que lo diferencia de los otros, de sus iguales; implica tener un valor superior de conocimiento o destreza. Para estos trabajadores artesanales estar en la posición del envidiado significa ser el único poseedor de aquel bien preciado, que, a su vez, debe ser resguardado. Savater (2004) define al envidiado de la siguiente manera:

Hoy en día ser envidiado es un valor, una forma de prestigio, porque, en definitiva, quien nos envidia nos ofrece un relativo homenaje. Uno se siente halagado pues se siente elevado a una posición superior al que lo envidia. Por lo tanto, y aunque parezca un juego de palabras, no sólo envidiamos una serie de cosas, sino también la condición de envidiados. (p. 65) 


\section{Una triada de riesgo}

Ahora bien, en el medio artesanal se dan algunas dinámicas por las cuales los saberes artesanales se han visto en riesgo. Por un lado, se presentan las intervenciones de los diseñadores y las instituciones promotoras de mecanismos que incentivan la comercialización por encima de las dinámicas del trabajo y creatividad de los artesanos. Con estas, se rompen las dinámicas del trabajo pausado al ritmo del artesano, en el que naturalmente no se miden tiempos, es decir, "su jornada no está dividida por un horario rígido sino por un ritmo que tiene más que ver con el del cuerpo y la sensibilidad que con las necesidades abstractas de la producción" (Paz, 1997, p. 138).

Los diseñadores son personas foráneas que imponen colores, diseños y elementos artesanales definidos; cuando requieren trabajos artesanales, especifican los tamaños, colores, formas y diseño para que la artesana elabore la pieza bajo estas delimitaciones. Por consiguiente, se desconocen los valores tradicionales tanto del hacer, como de los hacedores, quienes, al seguir y cumplir las directrices del diseñador, pierden la oportunidad de elaborar el objeto bajo sus propias pautas; se excluye su capacidad de decisión, investigación y creación.

Por otro lado, normas como la Ley 23 de 1982, o Ley de Derechos de Autor, y los planes especiales de salvaguardia se mantienen con regularidad fuera del alcance de los artesanos. Las leyes no tienen en cuenta las dinámicas internas de las prácticas artesanales de creación y los planes especiales no incluyen a artesanos que trabajen individualmente, sino solo a quienes trabajen en colectividad o en gremios. Así mismo, el artesano no cuenta con el apoyo de orientación oportuno al acceder a plataformas virtuales con las cuales puede acceder a la información sobre sus derechos o sobre los pasos para el registro de sus creaciones; tampoco cuenta con guías que puedan responder sus dudas acerca de los procesos y legislaciones.

Así, teniendo en cuenta que la mayoría de las artesanas tunjanas trabaja individualmente, en solitario desde su taller, y no están al tanto de leyes o planes de salvaguardia, cabe decir que sus propios mecanismos resultan funcionales, pues son los elementos que tienen a su alcance como medida de protección de sus saberes y elementos artesanales. Así, la envidia ha sido interpretada como como un mecanismo humano usado por las artesanas para salvaguardar, conservar y regular sus conocimientos.

Ahora bien, teniendo en cuenta que la envidia trae consigo el celo, es preciso mencionar la presencia de un tercer elemento: el silencio. "El silencio concede, en efecto, una oportunidad a lo simbólico, y permite una reflexión que conduce al entendimiento de las cosas, a no perder el hilo y a tomarse 
el tiempo necesario para la comprensión" (Breton, 2006, p. 54); solo quienes cuentan con la paciencia y la perseverancia son merecedoras de obtener la posesión deseada, de lo contrario la artesana dueña del conocimiento y de la pieza, tras hacer pausas reflexivas, guardará en el silencio sus conocimientos; las artesana preferirá reservarlos antes que darlos a quienes no los aprecian. El testimonio de María Cristancho es muestra de ello: "Alguna vez les enseñaba a las chicas jóvenes a bordar las albas, pero eso se cansan, ¡Ahhhhhhh! esa pereza que les ¡Daaaa! Todo el día así. Ellas quieren es aprender algo rápido" (comunicación personal, 6 de octubre de 2016). El bordado es una técnica que requiere tiempo, dedicación, concentración y amor por el oficio; quien demuestra su verdadero deseo por aprenderlo y practicarlo se hace digna de enseñar.

Así, pues, celo y silencio son usados para regular y reservar el conocimiento a quienes son merecedores de las enseñanzas, habilidades y objetos artesanales. A su vez, estos dos elementos exigen que los saberes, habilidades $\mathrm{u}$ objetos sean reconocidos como propios, como parte de la cultura propia y del aprendizaje recolectado en el hogar, la escuela y la experiencia.

Entonces, tanto celo como silencio juegan un papel importante en la transmisión de saberes. Este silencio hace parte del celo en el momento en que se desea o no compartir la posesión envidiada, permitiendo o prohibiendo la circulación del conocimiento entre los interesados del saber. En otras palabras, la artesana tantea con su mirada, examina, intuye y concluye si el aprendiz puede aprender. De lo contrario, como concluye David Breton respecto al silencio, "es secreto lo que sella el silencio" (Breton, 2006, p. 89).

El silencio es una forma de comunicación reflexiva que permite mantener el saber o elemento artesanal dentro de su círculo de confianza, actuando como mecanismo de protección y muralla en la transmisión del bien admirado. Así, es importante tener en cuenta que:

Las relaciones sociales exigen permanentes pruebas de confianza. Una evaluación subjetiva de su conducta futura justifica o no el que alguien se comprometa en un proyecto. [...]; pero el acuerdo se basa en el hecho de que él solo está capacitado para decidir lo que pretende hacer público respecto a sí mismo. (Breton, 2006, p. 89)

De esta manera, si hay envidia, hay celo; si existe celo, hay silencio; y si persiste el silencio, existe un secreto. Aquí es cuando el secreto puede representar un riesgo, pues el saber o el objeto artesanal solo se comparte con un reducido círculo de confianza, en quienes se manifiesta el amor y deseo por el oficio. Se "consolida una posición de relación o estatutaria, al 
tener a los demás alejados de una información que modificaría su existencia si saliese a la luz" (Breton, 2006, p. 95). Por consiguiente, como lo menciona Breton (2006), el secreto "constituye una reserva de poder" (p. 91), al hacer que el poseedor del secreto sea quien tiene el poder:

El secreto transforma un saber en privilegio. El silencio que le acompaña es un poder, una forma de distanciar al otro, que lo ignora sin saber incluso que existe o, bien al contrario, que intenta apropiárselo al haber barruntado su existencia. (p. 95)

La evaluación que se hace respecto a quién enseñar y a quién no, es esclarecida por las bordadoras: se enseña a quien muestra la paciencia por querer aprender sin desfallecer ante el primer aviso de error; no se enseña a quien de manera apresurada desea dar puntadas, sin escuchar ni observar con cautela lo que se desea. Es algo que se nota, es un principio de observación.

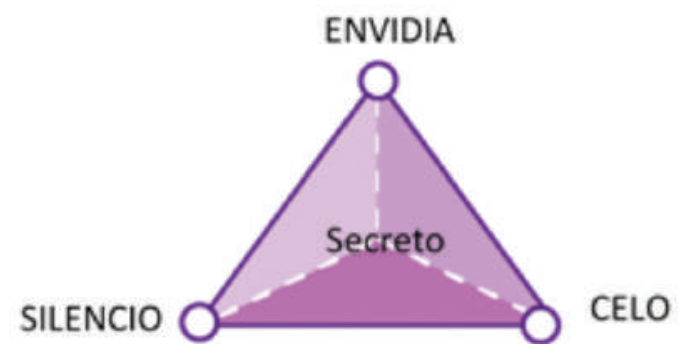

Figura 8. Triada envidia - celo y silencio.

En suma, la triada envidia - celo - silencio (Figura 8) moldea y respalda la salvaguardia del saber, en tanto que este se comparte con quien se desea. De tal manera, el conocimiento se entrega, se ofrece a quien ha sido perseverante y ha demostrado que goza de paciencia y respeto por el oficio, siempre al cuidado de conservar en cada puntada la delicadeza del saber aprendido. Se requiere paciencia para repetir una y otra vez la puntada, en el silencio acompañado, hasta que la puntada queda como debe quedar según su maestra, de lo contrario, si hay algo que no concuerda, se repite nuevamente; se requiere del conjunto maestra-aprendiz, para dejar en claro que solo se enseña a quien quiere aprender y que no todo el que quiere aprender merece o debe ser enseñado.

Mas, al mismo tiempo, esta triada conlleva un riesgo respecto a la transmisión de los conocimientos, ya que el artesano es quien elige con 
quién quiere compartirlos y de qué manera transformarlos. Así, el círculo de confianza se cierra cada vez más y el secreto del artesano no se da a conocer; los saberes, conocimientos y elementos artesanales quedan guardados en la memoria del sabedor. Esto suele ocurrir con las manifestaciones artesanales: los sabedores de avanzada edad son quienes portan los conocimientos y en ocasiones no los trasmiten a otros, llevando al olvido ciertas prácticas que eran importantes para la comunidad.

\section{Conclusiones}

A grandes rasgos, no se pretende que la envidia sea reconocida como una ley ni como un sentimiento negativo, sino, más bien, comprender que este es un mecanismo natural en los artesanos, que incentiva la creatividad en la medida en que es una herramienta de observación, medición y emulación de saberes. A la vez, se pretende que dicho mecanismo sea reconocido como un valor, ya que el envidiado goza de un prestigio frente a los demás artesanos, siendo este, el único poseedor de un bien preciado.

Los artesanos viven alejados de plataformas virtuales y al tanto de leyes que puedan proteger su conocimiento y elementos artesanales. De esta manera, gran parte de ellos optan resguardar sus conocimientos por medio de un conjunto natural: la triangulación planteada como envidiacelo-silencio, que es utilizada para proteger sus elementos preciados y sus saberes artesanales de personas que no aprecian la laboriosidad del oficio y de quienes desean robar no solo sus ideas sino, además, sus elementos artesanales, en este caso sus dechados, o quienes se encuentran fuera de sus círculos de confianza.

Por ello, la triangulación expuesta se convierte en el mecanismo humano innato con el que los artesanos defienden y configuran la salvaguardia de sus saberes y posesiones. Dicho mecanismo no necesita portal web, formulario, dinero, ni tiempo. La envidia, junto con el celo y el silencio, permite regular de manera natural quiénes pueden acceder y a quiénes se desea transmitir las posesiones (conocimientos y objetos). Así, el sentimiento de envidia se interpreta como un mecanismo que ha sido utilizado por los artesanos en remplazo de las leyes y los planes que no los cobijan del todo y que no responden a sus intereses.

Estas leyes no solo resultan complejas para los artesanos, en cuanto a su comprensión e incorporación; también, en ellas se manejan mecanismos alejados de las dinámicas sociales de los artesanos, de los talleres, de los modos de transmisión; es decir, no se comprende la magnitud del hacer artesanal, la invención, la enseñanza, el diálogo, la protección y la pérdida, 
entre otros. En la medida en que el artesano sienta que sus elementos artesanales no están protegidos de personas que no le dan la importancia necesaria, este continuará regulando y preservando de manera autónoma y natural su conocimiento y elementos artesanales, permitiendo únicamente el acceso a su círculo de confianza y alejándose de las leyes que dicen promover su protección.

No obstante, el mecanismo de salvaguardia utilizado por los artesanos - la envidia - genera riesgos en la transmisión de saberes, en la medida en que genera celo, silencio y secreto, siendo este último el motivo por el cual un saber puede permanecer guardado en las palabras de sus sabedores. Por ello, es preciso generar estrategias amigables para que surja en los artesanos el deseo de transmitir sus conocimientos a un círculo de confianza más amplio, a quienes deseen aprenderlos y recibirlos, que no busque satisfacer un interés de comercialización, sino que quiera transmitirlos a las nuevas generaciones. Es necesario que las leyes y los planes propendan por cambiar los mecanismos que proponen para la protección y salvaguardia del artesano; se requiere mejorar las dinámicas o estrategias de las leyes y planes para artesanos que se encuentran en minorías, dando prioridad a los modos de transmisión, elaboración, aprendizaje y diseño en los talleres artesanales.

\section{Referencias bibliográficas}

Breton, D.L. (2006). El silencio (2a. ed.). (A. Temes, Trad.). Madrid: Sequitur.

Centeno, S. (2017). Envidia, en Diccionario Filosófico de Centeno. Recuperado de https://sites.google.com/site/diccionariodecenteno/e/envidia

D'Arms, J. (2017). The Stanford Encyclopedia of Philosophy. (E.N. Zalta, Ed.) Recuperado de https://plato.stanford.edu/archives/spr2017/entries/envy /

García, M. (2014). Filosofía-Envidia. Recuperado de http://mauroalejo98.blogspot. com/2014/08/introduccion.html

Girbés, B. y Martín, R. (2015). Celos y envidia en el trabajo: una revisión de los últimos 20 años. Apuntes de Psicología, 33(3), 127-136.

Gómez-Redondo, C. (2017). El objeto patrimonial como símbolo. Midas (8).

Mandeville, B. (1982). La fábula de las abejas. México: Fondo de Cultura Económica.

Martínez, L.M. (2005). Celos y envidias: Emociones Humanas. Tesis, Universidad Nacional Autónoma de Mëxico, Coyoacán, México.

Matham, J. (1593). Envidia [Figura 7]. Recuperado de http://www.artvalue.com/auctionresult-matham-jacob-1571-1631-flander-the-seven-vices-1836450.htm

Mauss, M. (2009). Ensayo sobre el don: Forma y función del intercambio en las sociedades arcaicas. (J. Bucci, Trad.) Buenos Aires; Madrid: Katz.

Moncada, J.E. (2014). Mímesis en Platón y Adorno. EIDOS(20), 173-220.

Nietzsche, F. (s.f). Así habló Zaratustra. PlanetaLibro.net. Recuperado de http://planetalibro. net/leerlibro/nietzsche-friedrich-wilhelm-asi-hablo-zaratustra/3 
Paniagua, C. (2002). Psicología de la envidia. Revista de Humanidades Médicas, 1, 35-42.

Paz, O. (1997). La artesanía, entre el uso y la contemplación. Revista Colombiana de Psicología,11(34), 120-125. doi:doi: 10.15446/rcp

Savater, F. (2004). Los diez mandamientos en el siglo XXl. Tradicion y modernidad del legado de Moisés. (2 ed.). Barcelona, España: Random House Mondadori, S. A.

Savater, F. (13 de agosto de 2005). Los siete pecados capitales. Periódico El Clarin. Recuperado de https://www.clarin.com/

Sennett, R. (2008). El artesano. Barcelona: Anagrama.

Tresguerres, A.F. (2003). El Catoblepas. Revista Crítica del Presente. Recuperado de http://www.nodulo.org/ec/2003/n012p03.htm

Vergara, N. (2006). Objetos patrimoniales: consideraciones metafísicas. Alpha, (23), 37-56. doi:https://dx.doi.org/10.4067/S0718-22012006000200003

Vergara, N. (S.f). Objetos patrimoniales: consideraciones epistemológicas. Revista LIDER, 1, $35-42$.

Voltaire, D.F. (s.f). Envidia. Recuperado de https://www.e-torredebabel.com/Biblioteca/ Voltaire/envidia-Diccionario-Filosofico.htm 